Cahiers $d u$ MONDE RUSSE

\section{Cahiers du monde russe}

Russie - Empire russe - Union soviétique et États indépendants

$51 / 4 \mid 2010$

Sciences humaines et sociales en Russie à l'Âge d'argent

\title{
Andrej Portnov, Upražnenija s istoriej po ukrainski
}

Ioulia Shukan

\section{(2) OpenEdition}

Journals

Édition électronique

URL : https://journals.openedition.org/monderusse/7443

DOI : 10.4000/monderusse.7443

ISSN : $1777-5388$

Éditeur

Éditions de l'EHESS

Édition imprimée

Date de publication : 25 novembre 2010

Pagination : 810-814

ISBN : 978-2-7132-2316-7

ISSN : $1252-6576$

Référence électronique

Ioulia Shukan, «Andrej Portnov, Upražnenija s istoriej po ukrainski », Cahiers du monde russe [En ligne], 51/4 | 2010, mis en ligne le 09 décembre 2011, consulté le 03 septembre 2022. URL : http://

journals.openedition.org/monderusse/7443; DOI : https://doi.org/10.4000/monderusse.7443

Ce document a été généré automatiquement le 3 septembre 2022.

Tous droits réservés 


\title{
Andrej Portnov, Upražnenija s istoriej po ukrainski
}

\author{
Ioulia Shukan
}

\section{RÉFÉRENCE}

Andrej PORTNOV, Upražnenija s istoriej po ukrainski [Des usages instrumentaux de l'histoire à l'ukrainienne]. Moscou : OGI, Polit.ru, Memorial, 2010, 223 p.

1 Les politiques publiques symboliques, mémorielles et identitaires, menées en Ukraine depuis l'accession du pays à l'indépendance en 1991, se trouvent au cœur de l'ouvrage d'Andrej Portnov, historien et rédacteur en chef de la revue Ukraïna Moderna. Prenant la forme d'un recueil de quatre articles retravaillés pour l'occasion par l'auteur, l'ouvrage examine ces politiques sous différents angles : érection de monuments, construction du récit historiographique officiel et enseignement de ce récit à l'école, mais aussi situation de l'enseignement et de la recherche en sciences humaines, enfin réinterprétations de la grande famine des années 1932-1933. De nombreux exemples viennent illustrer le propos de l'auteur tout au long de l'ouvrage.

2 L'article intitulé « Des usages instrumentaux de l'histoire à l'ukrainienne », qui ouvre l'ouvrage, analyse les politiques mémorielles et identitaires conduites par les présidents Leonid M. Kravčuk (1991-1994), Leonid D. Kučma (1994-2005) et Viktor Juščenko (2005-2010). L'auteur relève ici l'absence de politiques publiques cohérentes en Ukraine postsoviétique, les trois chefs d'État ayant procédé à tâtons en matière symbolique et mémorielle, ce qui leur a permis avec plus au moins de succès d'éviter tout conflit national, linguistique ou religieux ouvert. Ce caractère fluctuant, situationnel et multivectoriel de l'action publique explique d'ailleurs l'extrême pluralisme de l'espace public ukrainien. À cet égard, la politique de « décommunisation » analysée dans l'article est particulièrement révélatrice. Définie en priorité par les autorités locales, elle connaît une grande disparité en fonction des régions. Ainsi en Galicie, région occidentale annexée à l'Ukraine soviétique en 1939, la décommunisation de l'espace public est aujourd'hui la 
plus aboutie, les statues de Lenin ayant été remplacées par celles des figures clefs du mouvement nationaliste ukrainien de l'entre-deux-guerres et les rues ayant été rebaptisées. Par contre, à Kyiv, elle n'a jamais été menée à son terme, des monuments et des noms de rue soviétiques et postsoviétiques coexistant dans l'espace public de la capitale.

3 Ces politiques symboliques et mémorielles reposent en partie sur le récit historiographique officiel alternatif à l'historiographie soviétique et sur lequel Portnov porte un regard critique. Parmi ses principales caractéristiques, l'auteur identifie la construction d'un lien de continuité entre l'Ukraine postsoviétique et présoviétique, ce qui suppose de mettre entre parenthèses la période soviétique et de nier la contribution de l'URSS à la constitution du territoire ukrainien dans ses frontières actuelles. Si la Grande Guerre patriotique est intégrée à la nouvelle historiographie officielle, l'accent est cependant mis sur l'histoire sociale de la guerre et les souffrances des populations. La résistance des membres de l'Organisation des nationalistes ukrainiens (OUN) et de l'Armée insurrectionnelle ukrainienne (UPA) tant à l'occupation soviétique que nazie est également mise en avant, alors que des épisodes moins glorieux de leurs activités, tels que les actions punitives anti- polonaises conduites en Volhynie ou encore la participation à des actions punitives nazies à l'encontre des populations juives, sont passés sous silence.

4 Les usages instrumentaux et différentiels de ce nouveau mythe national par les trois chefs d'État garantissent paradoxalement, d'après l'auteur, la stabilité de la société ukrainienne, dans la mesure où ils interdisent tant à ce mythe qu'à l'ancienne historiographie soviétique de s'imposer définitivement comme récit dominant. L'auteur montre ainsi que, si sous la présidence de L. Kravčuk la priorité est accordée au récit historiographique national, ce qui n'est pas sans conduire à des tensions notamment confessionnelles ${ }^{1}$, l'action publique dans ce domaine se situera plutôt au centre sous le président Kučma. Ce positionnement ne fait d'ailleurs qu'accroître l'ambivalence de la politique menée, que cela concerne l'appui des autorités à la langue russe sur fond de reconnaissance de l'ukrainien comme seule langue officielle, ou encore la pratique de régionalisation des événements commémoratifs décrite par l'auteur, les festivités consacrées à l'anniversaire de la création de la République populaire d'Ukraine de l'Ouest ayant lieu à Lviv alors que l'anniversaire du Premier secrétaire du parti communiste ukrainien, V.Ščerbitskij, était célébré à Dnepropetrovsk, à l'est de l'Ukraine. Cette ambivalence de l'action publique contribue fortement à la production du mythe des "deux Ukraines ", c'est-à-dire d'une profonde division du pays entre l'Ouest proeuropéen et l'Est prorusse et antilibéral, mythe habilement exploité par l'élite politique pendant et après la révolution orange et qui correspond peu, d'après l'auteur, à la réalité.

5 Enfin la présidence de V.Juščenko est également marquée par l'ambiguïté en matière symbolique et mémorielle, du fait notamment de l'attribution de décorations d'État à des personnalités clefs tant de l'histoire nationale que soviétique ou encore d'appels à la réconciliation des vétérans ayant combattu dans l'armée soviétique comme dans la résistance nationaliste pendant la Seconde Guerre mondiale. Dans le même temps, à la différence de ses prédécesseurs, Juščenko a développé une action publique plus conséquente, notamment en ce qui concerne l'obtention de la reconnaissance internationale de la grande famine des années 1932-1933 en tant que "génocide de la nation ukrainienne » ou encore l'institutionnalisation de cette politique mémorielle par le biais de la création en 2006 de l'Institut de l'histoire nationale. Cette action a 
cependant rencontré de fortes résistances de la part de ses adversaires politiques, incarnés par le Parti des régions ou encore le Parti communiste d'Ukraine. L'auteur donne ici plusieurs exemples de la « guerre des monuments» dans les régions de l'Est (enlèvement des enseignes commémoratives dédiées à l'OUN et à l'UPA, velléités d'érection de monuments à la gloire des empereurs russes Pierre le Grand ou Catherine II), révélatrice de l'instrumentalisation de l'histoire par les principaux protagonistes politiques. L'auteur conclut que, depuis 1991, les élites ukrainiennes peinent à percevoir l'Autre non pas comme une menace mais comme une chance pour un pays aussi diversifié que l'Ukraine.

6 Le deuxième texte, intitulé «Le milieu scientifique et les cultures académiques en Ukraine de nos jours ", porte un regard critique sur la situation de l'enseignement et de la recherche en sciences humaines, notamment de l'histoire. L'auteur commence par s'étonner de l'extrême facilité avec laquelle ses collègues, historiens spécialistes de l'histoire du parti communiste, se sont reconvertis en artisans de la nationalisation de l'histoire ukrainienne après 1991. Cette reconversion n'a cependant pas entraîné de changements de méthodes, le manque de recul et l'absence de points de vue alternatifs caractérisant toujours les travaux historiographiques ukrainiens. Portnov s'inquiète ensuite de la tendance à la "régionalisation» de l'enseignement et de la recherche scientifique en Ukraine, c'est-à-dire de la constitution de communautés académiques fermées, fonctionnant en vase clos et connaissant une baisse sensible de la qualité de leur production académique (articles publiés de niveau insuffisant, absence de débats lors des conférences scientifiques, faible audience des revues régionales, etc). Il s'alarme, enfin, de la dévalorisation des diplômes nationaux qui s'acquièrent facilement contre une rétribution financière, d'une large acceptation $d u$ plagiat et des pratiques bureaucratiques en vigueur au sein de la Commission d'attestation supérieure (VAK), chargée d'établir les normes de la production scientifique et de veiller à leur maintien. Portnov s'interroge sur la capacité de l'enseignement et de la recherche ukrainiens à sortir de cette situation qu'il qualifie lui-même de catastrophique.

7 Sous le titre "Terra Hostica: la Russie dans les manuels ukrainiens d'histoire ", le troisième article analyse le récit historiographique officiel tel qu'il est enseigné du collège au lycée (de la classe de $5^{\mathrm{e}}$ à celle de $11^{\mathrm{e}}$ dans le système ukrainien) dans les manuels d'histoire recommandés par le ministère de l'Éducation nationale. L'auteur relève de nombreuses faiblesses de ces manuels, telles que l'absence de points de vue alternatifs et d'efforts de restitution du contexte de l'époque, la tendance à essentialiser le territoire de l'Ukraine contemporaine et de sa structure ethnique et surtout la démarche téléologique de l'histoire ukrainienne. Cette démarche suppose, d'après l'auteur, d'identifier la construction de l'État-nation ukrainien en tant qu'objectif ultime pour ensuite revoir l'histoire à la lumière de cet objectif en la présentant comme un avancement inéluctable dans sa direction. Cette méthode a deux conséquences. Elle exige d'abord d'établir un lien de continuité souvent artificiel entre les différentes expériences étatiques ukrainiennes, en commençant par la Russie kiévienne, nationalisée pour le coup car présentée comme le premier État ukrainien, en passant par le Hetmanat cosaque et en terminant par les formations étatiques ukrainiennes des années 1917-1921. Elle entraîne également une représentation des relations avec la Russie comme ayant été conflictuelles de tout temps. La Russie est ainsi décrite comme un ennemi militaire féroce, empiétant sur les traditions démocratiques des territoires ukrainiens, et contre les agressions de laquelle les populations ukrainiennes pacifiques ont toujours été contraintes de se défendre. À cet égard, la Russie joue ici le rôle de l' 
«Autre significatif» dans la construction identitaire ukrainienne: l'Autre auquel les Ukrainiens se confrontent et par rapport auquel ils se différencient. Mais, en conclusion, l'auteur affirme que la portée unificatrice des manuels ne doit pas être surestimée, car les enseignants utilisent ces derniers de manière variable en fonction des régions. Les usages différentiels des manuels d'histoire restent donc encore à explorer.

Enfin, le dernier article («Le Holodomor de 1932-1933 comme défi à la théorie du génocide : généalogie intellectuelle des débats contemporains ») est consacré à la grande famine de 1932-1933 et aux débats sur son interprétation et sa qualification de génocide commis à l'encontre des Ukrainiens. Après avoir retracé les usages internationaux et académiques du terme de "génocide", l'auteur présente les principaux points de désaccord des historiens quant au caractère intentionnel ou non de la famine, ainsi qu'en ce qui concerne sa cible principale (populations rurales dans d'autres régions de l'URSS ou populations principalement ukrainiennes, ce qui accrédite le qualificatif de génocide commis à l'encontre des Ukrainiens). Face à cette dernière thèse d'une extermination planifiée des Ukrainiens, Portnov met en garde contre le piège d'ethnicisation de la grande famine, les Ukrainiens étant définis en tant que catégorie essentialiste sans tenir compte de leurs différences sociales. Il pointe également l'absence de recherche microhistorique sur la famine, sur sa mise en œuvre au niveau régional, notamment par les communistes ukrainiens, et surtout sur le fonctionnement des stratégies d'oubli de ces événements tragiques et de leur effacement des mémoires individuelles. Enfin, il évoque l'instrumentalisation politique de la grande famine sans cependant l'analyser, alors que celle-ci a marqué non seulement les politiques mémorielles et symboliques sous la présidence de V.Juščenko, mais également la politique étrangère ukrainienne et plus particulièrement les relations avec la Russie entre 2005 et 2010.

\section{NOTES}

1. La volonté des autorités tant politiques qu'ecclésiastiques d'obtenir le statut d'Église autocéphale pour l'Église orthodoxe ukrainienne avait abouti en 1993 à une scission au sein de son épiscopat entre le patriarcat de Moscou et le patriarcat de Kyiv. Cette scission est venue renforcer le pluralisme confessionnel, mais aussi national et politique, avec la coexistence de deux (ou trois) Églises orthodoxes (Église orthodoxe relevant du patriarcat de Moscou et celle relevant de celui de Kyiv, ainsi que l'Église orthodoxe autocéphale), de l'Église gréco-catholique ukrainienne et de l'Église catholique. 